\title{
A FUNDAMENTAÇÃO DAS DECISÕES JUDICIAIS NO NOVO PROCESSO CIVIL BRASILEIRO: UMA QUESTÃO DE HERMENÊUTICA
}

\section{Sheyla Yvette Cavalcanti Ribeiro Coutinho*}

Resumo: A guinada paradigmática para o Estado Democrático de Direito esteve ancorada em uma teoria material de valores, que buscou empreender a concretização dos valores constitucionais. A existência [ou ausência de nulidade] de uma "decisão judicial não fundamentada" (a contrário dos artigos 499, §1 ${ }^{\circ}, 926$ e 927 do CPC) significaria promover um discurso irracional de poder, onde os meios do julgador prevaleceriam sobre o télos do contrato social. O texto dialoga com a exigência da fundamentação das decisões judiciais no CPC/2015, a partir da Teoria dos precedentes. Fundamentar é questão hermenêutica de materialidade democrática e de devido processo legal substancial.

Palavras-chave: Decisão Judicial; Teoria Hermenêutica; Hermenêutica Filosófica; Precedentes; Hans-Georg Gadamer.

\section{THE BASIS OF JUDICIAL DECISIONS IN THE NEW BRAZILIAN CIVIL CASE: A QUESTION OF HERMENEUTICS}

\begin{abstract}
The paradigm shift for the Democratic Rule of Law was anchored in a material theory of values, which sought to undertake the realization of constitutional values. The existence (or lack of nullity) of an "unsubstantiated judicial decision" would promote an irrational discourse of power, where the means of the judge would prevail over the social contract. The text dialogues with the requirement of the basis of judicial decisions in CPC / 2015, based on the Theory of precedents. Grounding is a hermeneutic question of democratic materiality and due substantive legal process.
\end{abstract}

Keywords: Judicial decision; Hermeneutical Theory; Philosophical Hermeneutics; Precedents; Hans-Georg Gadamer.

\footnotetext{
* Sheyla Yvette Cavalcanti Ribeiro Coutinho. Analista Judiciária da Justiça Federal de Sergipe. Mestre pela UFPE. Especialista pela UNICAP. Professora Universitária.
} 


\section{CONSIDERAÇÕES INTRODUTÓRIAS: O PROCESSO E SEU TEMPO}

A Lei processual sofreu sistemáticas alterações ao longo da dialética histórica. Desde as primeiras Constituições escritas do final do século XVIII, até meados do Século XX (Fim da $02^{\mathrm{a}}$ Guerra Mundial), a norma era considerada o texto da lei, desconectada de seu programa normativo. A processualística do liberalismo clássico pugnava uma vasta rede de garantias às liberdades do indivíduo, diante das possíveis ingerências do Estado. Dessa forma, pela lei, os poderes de Estado estavam impedidos de proferirem decisões arbitrárias, agressivas aos direitos e liberdades dos cidadãos. Nessa época, o processo tornou-se inteligível dentro de uma acepção de igualdade formal (na lei).

No âmbito jurídico-epistemológico, sobressaltava-se o paradigma representacional, que concebia a interpretação como procedimento dotado de fases, capaz de acomodar as decisões "de forma dedutiva". A premissa maior era o enunciado normativo; a premissa menor eram fatos. Seguidamente, a consequência, que era a aplicação da norma ao caso concreto (subsunção normativa). A diferenciação dos conteúdos fático-normativos tornava-se despicienda, em detrimento do paradigma abstrato e universalizante da lei, com relevo nos padrões (standarts) dominantes, próprios da concepção formal do princípio da igualdade.

Com o final da segunda guerra, inicia-se a base de uma "virada epistemológica" também no campo sociojurídico. Essa "nova" abordagem teórica, cunhada de neoconstitucionalismo ${ }^{2}$ incorpora o cabimento dos campos de "valoração" e de "justiça", com sua centralidade marcada pela Força Normativa da Constituição ${ }^{3}$, amparada, em especial, pela

\footnotetext{
${ }^{1}$ A guerra mostrara que os fatos "da vida" e a sua rebeldia imperavam diante dos esquemas-base da racionalidade positiva, quais sejam, abstração e dedução lógica. Ocorre o que Lyotard (1993, p. 03) definiu como a deslegitimação dos grandes relatos da modernidade (metadiscursos modernos).

${ }^{2}$ Ou pós-positivismo jurídico - principiologia calcada na dignidade humana, na solidariedade social e nos direitos fundamentais. A conceituação aqui utilizada é de Luiz Guilherme Marinoni (2008, p. 49): “A obrigação do jurista não é mais apenas a de revelar as palavras da lei, mas a de projetar uma imagem, corrigindo-a e adequando-a aos princípios de justiça e aos direitos fundamentais. (...). O neoconstitucionalismo exige a compreensão crítica da lei em face da Constituição (...). Essa transformação crítica da lei, ao dar o jurista uma tarefa de construção - e não de simples revelação - confere-lhe maior dignidade e responsabilidade, já que dele se espera uma atividade essencial para dar efetividade aos planos da Constituição, ou seja, aos projetos do Estado e às aspirações da sociedade" Adverte-se, contudo, a utilização indiscriminada em face da utilização indiscriminada da expressão.

${ }^{3}$ A tópica no Direito Constitucional Contemporâneo tem na Alemanha os seus grandes Mestres, entre os quais figuram: Konrad Hesse (Força Normativa da Constituição); Friedrick Müller com um novo método de interpretação constitucional, que ele mesmo denominou de estrutural-funcionalista [Normativo-estruturante] e Häberle [a Constituição aberta - sistema de interpretação constitucional mais antiformalista que se conhece]. Segundo Konrad Hesse, as normas constitucionais possuem uma força própria (densidade material): "Quanto mais a ordem constitucional corresponde às realidades da situação histórica, quanto maior é a disposição de reconhecer os conteúdos da Constituição como obrigatórios e quanto mais firme é a disposição de atualizar esses conteúdos, também contra as resistências, tanto mais e mais seguro aquelas ameaças poderão ser evitadas ou rechaçadas" (HESSE apud STRECK, 2005, p.252). A interpretação constitucional é concretização, na qual o concreto é individualizado: concretizar o sentido da norma dentro das condições de uma situação de fato determinada. Em
} 
axiologia da existência humana digna e nos princípios dela derivados. Com essa abordagem, a ética e os valores começam a voltar ao Direito.

A guinada paradigmática ${ }^{4}$ do liberalismo clássico para o Estado Democrático de Direito exige a socialidade e a eticidade das relações sociojurídicas, com seus substratos e seus limites ancorados em uma teoria material de valores que busque empreender a concretização do preceito constitucional, sem reduzi-lo ao "charme" do decisionismo arbitrário ${ }^{5}$. Essa guinada, no Direito nacional, ao contrário de possibilitar maior extensão normativa de concreção, para a efetividade dos direitos fundamentais, vem, por "estelionato jurídico" de seus alcances, servindo para justificação de decisões amplamente discricionárias - "maquiavélicas"6 - com base em um processo de discricionariedade desregrada do intérprete-juiz na aplicação da norma. A preocupação em torno dessa questão é um alerta de que não se pode, simplesmente, adotar uma postura de passividade em relação ao problema do relativismo, mas que é necessária a afirmação da necessidade de uma "razão crítica", que seja responsável por delimitar a viabilidade [validade ética], ou não, de determinados alcances da norma-princípio no Sistema Jurídico Constitucional.

Essa perspectiva não significa dar azo ao individualismo exacerbado e [ou] à figura do “juiz empoderado", que julga motivando as próprias razões, previamente eleitas. Um poder amplamente discricionário significaria o fim do próprio Estado de Direito e do Princípio

detrimento do método tópico-problemático, que "valoriza" o problema, o método hermenêutico-concretizador valoriza o comando normativo e sua individualização no mundo. Interpretar e aplicar são um único processo. Para Hesse, "uma lei não deve ser declarada nula quando ela pode ser interpretada em consonância com a Constituição. Essa consonância existe não só, então, quando a lei, sem uma consideração dos pontos de vista jurídicoconstitucionais, admite uma interpretação que é compatível com a Constituição" (HESSE apud STRECK, 2005, p.252). "Quanto maior é a disposição para se reconhecer os conteúdos da Constituição, como obrigatórios, e, quanto mais firme é a disposição de atualizar esses conteúdos, também contra as resistências, tanto mais, e mais seguro, aquelas ameaças poderão ser evitadas ou rechaçadas". (Cfe. HESSE apud Lênio Luiz STRECK, Hermenêutica jurídica e $(m)$ crise. Porto Alegre: Livraria do Advogado, 2005, p.252).

${ }^{4}$ Sobre a questão dos paradigmas adverte Gadamer (1998a, p.14): "Sabemos que, mesmo nas ciências empíricas, como Kuhn em particular o demonstrou, os conhecimentos novamente estabelecidos encontram resistências e na verdade permanecem por muito tempo 'ocultos' pelo paradigma dominante".

${ }^{5}$ É o cenário do que Paulo Bonavides (2008, p.595): expõe como uma "Nova Hermenêutica de Concretização", oriunda do Princípio da Unidade da Constituição: “A Corte de Karlsruhe sentenciou: 'Não se pode considerar insuladamente uma estipulação singular da Constituição, nem pode ser ela interpretada 'em si mesma', senão que deve manter 'conexão' de sentido com as demais prescrições da Constituição, formando uma unidade interna"”.

${ }^{6}$ Utiliza-se a expressão "Juiz maquiavélico", para "diagnosticar”, aquele que promove suas decisões, segundo seus fins (unilateralidade), com base nos seus próprios meios (motivação pessoal), ancorado, de fato, em um discurso de irracionalidade egocêntrica, ao contrário do que se propõe na Teoria Material da Constituição, albergada na extensão objetivamente valorada dos princípios. Esse “desgoverno de Juízes maquiavélicos” é o que Paulo BONAVIDES (2008, p. 646) chama de "governo de juízes" ou de "ditadura constitucional da toga”. Nessa direção, Lenio STRECK (2005, p. 310) elucida que não se deve admitir um processo de discricionariedade desregrada do intérprete na aplicação da norma: “(...) a afirmação 'a norma é (sempre) o produto da atribuição de sentido a um texto' não pode significar que o intérprete esteja autorizado a 'dizer qualquer coisa sobre qualquer coisa" [grifo nosso]. 
Fundamental que lhe dá suporte - a Legalidade. Um Estado de princípios discricionários, resultado de uma discursividade egocêntrica, que extrapola a devida fundamentação constitucional, esvazia a legalidade.

Nesse sentido, a possibilidade da existência [ou da ausência de nulidade] de uma “decisão judicial não fundamentada” (a contrário dos artigos 499, §1º, 926 e 927 do CPC) significaria promover um discurso irracional de poder, onde os meios do julgador prevaleceriam sobre o télos do contrato social outorgado pela Carta Constitucional. Nada mais do que um "governo de juízes" ou uma "ditadura constitucional da toga" (BONAVIDES, 2008, p. 646).

Esse texto dialoga com a específica exigência da fundamentação das decisões judiciais no processo civil brasileiro, a partir do questionamento sobre os "fundamentos determinantes" dos precedentes. Fundamentação judicial que é questão hermenêutica de materialidade democrática e de devido processo legal constitucional em sua dimensão substancial.

\section{DO LEVIATÃ AO CONSTITUCIONALISMO CONTEMPORÂNEO: DE VOLTA AO COMEÇO?}

No Leviatã (1651), Escreve Hobbes (2015, p. 239-240): “(...) A Lei Civil apenas informa o nome da pessoa que dá a Ordem, (....), a Persona Civitatis, a Pessoa do Estado. O Legislador é somente o Soberano, seja ele um homem, (....), ou uma Assembleia de homens (...). (...) O Soberano de um Estado não está sujeito às Leis Civis. (...)”.

Era a lógica do Leviatã, na qual o Poder de Estado centralizava-se na figura do Soberano. A soberania nasce dessa relação de supremacia de poder entre o Supremo Poder do Soberano e a posição dos súditos, a quem não restava muita liberdade civil, haja vista o pacto social que firmaram entre si, a bem da própria preservação da história, assim: "Os homens, para alcançar a paz e a própria preservação, fizeram um Homem Artificial, o qual chamaram de Estado; da mesma forma fizeram Grilhões Artificiais, chamados de Leis Civis, as quais eles mesmo, por Pactos mútuos, fixaram uma das extremidades aos lábios de um Homem ou de uma Assembleia (a quem investiram com o Poder Soberano) e a outra extremidade ataram às suas próprias orelhas" (HOBBES, 2015, P. 193).

Para Hobbes (2015, p. 241), a Lei Civil é regulação da vida humana no Estado, onde o homem abandona seu estado de natureza, assinando e estabelecendo o contrato social. A 


\section{A FUNDAMENTAÇÃO DAS DECISÕES JUDICIAIS NO NOVO PROCESSO CIVIL BRASILEIRO: UMA QUESTÃO DE HERMENÊUTICA}

liberdade "natural" cedia espaço à liberdade na forma da lei civil. Lei essa que estava nas mãos de um Soberano, a quem cabia decidir o direito segundo sua vontade.

A ideia de Constitucionalismo Moderno surge, efetivamente, com a concepção de limitação do Poder de Estado, ou seja, surge com a regulamentação de uma série de direitosgarantia dos cidadãos, diante do arbítrio do Estado. "A grande mão" do Leviatã, monstro 7 que assombra as liberdades subjetivas, encontra barreiras no dever absenteísta do Estado.

São marcos do Constitucionalismo Moderno a Constituição dos Estados Unidos da América (1787) e a Constituição da França (1791): “A ideia da organização constitucional do Estado começou a ganhar vulto no século XVIII com o chamado movimento constitucional, impulsionado pelas revoluções americana e francesa" (CANOTILHO, 1993, p. 61).

De outro lado, podem-se destacar como "embriões" do Constitucionalismo moderno alguns documentos escritos, mas que não chegavam a ser Constituições como é o caso dos pactos: a) Magna Carta Inglesa (Magna Charta Libertatum - Século XIII, em 1215, data em que os barões do Reino de Inglaterra impuseram a João Sem Terra a Magna Carta, ainda na Idade Média; b) Petitio of Rights (1628 - apesar de seu caráter meramente declaratório ("petição"), representou uma tomada de posição do Parlamento sobre os princípios fundamentais das liberdades civis); c) Bill of Rights (1689). Todos esses documentos gestaram uma série de mecanismos de proteção aos direitos fundamentais da pessoa humana, limitando a ingerência estatal na esfera privada.

Esses documentos escritos configuraram aquilo que José Joaquim Gomes Canotilho (1993, p. 61) chama de "pré-história constitucional”, resultante do "processo de sedimentação do constitucionalismo britânico". Para o Mestre Português: “O Instrument of Government (1653) de Cromwell é considerado como a primeira verdadeira constituição escrita, aproximando-se das fórmulas constitucionais autoritárias da época contemporânea”.

O Constitucionalismo Moderno manteve forte viés liberal, amparando valores como a liberdade, a propriedade privada e a exigência de uma política absenteísta do Estado, consagrando limites à intervenção do Estado na vida privada. Para Canotilho (1993, p. 63), o chamado conceito ideal de constituição (extraído de Carl Schmitt):

\footnotetext{
${ }^{7}$ Leviatã é nome que se atribui a um "monstro marinho" citado na bíblia em Jó 3.8 e Jó 40.25. Hobbes aproxima a figura do Soberano a figura desse monstro mitológico - o Leviatã, a quem todos deviam submissão e temiam.
} 
identifica-se fundamentalmente com os postulados político-liberais, considerando-se como elementos materiais caracterizadores e distintivos os seguintes: (a) a constituição deve consagrar um sistema de garantias da liberdade (está essencialmente concebida no sentido do reconhecimento de direitos individuais e da participação dos cidadãos nos actos do poder legislativo através dos parlamentos); (b) a constituição contém o princípio da divisão de poderes, no sentido de garantia orgânica contra os abusos dos poderes estaduais; (c) a constituição deve ser escrita (documento escrito). [os grifos são nossos].

Com o pós-Segunda Guerra Mundial, "surge” o que a Doutrina conceituou como neoconstitucionalismo, chamado por alguns de constitucionalismo "contemporâneo", constitucionalismo "avançado" ou constitucionalismo "de direitos", que representou uma resposta às atrocidades cometidas pelos regimes totalitários (nazismo e fascismo), tendo como escopo a dignidade da pessoa humana.

O "neoconstitucionalismo" eclodiu com a decepção das meta-narrativas iluministas de Verdade, Igualdade, Liberdade e Felicidade, depois do segundo pós-guerra. Surge com ele, sobretudo, um Estado de direito material, preocupado com os valores sociais, como a garantia da justiça material, da igualdade, da segurança, etc. Nele, há a vinculação dos Poderes de Estado aos direitos fundamentais; ao princípio da proporcionalidade; aos princípios fundamentais constitucionais; ao condicionamento da existência da legalidade às exigências da legitimidade. Do ponto de vista processual constitucional contemporâneo ${ }^{8}$, ancorado no que se concebe, de uma forma geral, como "principiologia dos valores", a norma jurídica contida na sentença "não pretende ser pensada como uma norma que regula o caso concreto, nem mesmo quando é fruto do controle constitucional; (...)" (MARINONI, 2008, p. 101). Essa norma está longe de ser a particularização da lei. Continua a esclarecer Marinoni (2008, p. 101):

[Essa norma] pode ser dita uma norma jurídica criada diante do caso concreto, mas não uma norma individual que regula o caso concreto. (...) [A norma jurídica] serve para explicar a conformação da lei e da legislação aos princípios constitucionais de justiça e aos direitos fundamentais [o grifo é do autor].

Por isso, considerar a principiologia constitucional, a partir da fundamentalidade material da Constituição, ancorada na força normativa dos princípios, não pode significar, de

\footnotetext{
${ }^{8}$ Os princípios foram trazidos para o centro do sistema constitucional e "ganharam" o status jurídico de norma, deixando o arcabouço meramente valorativo, sem aplicabilidade e eficácia. Essa perspectiva "pós-positivista" e principiológica do Direito deu ensejo à formação de uma moderna hermenêutica constitucional. (BARROSO, 2006, p. 34).
} 


\section{A FUNDAMENTAÇÃO DAS DECISÕES JUDICIAIS NO NOVO PROCESSO CIVIL BRASILEIRO: UMA QUESTÃO DE HERMENÊUTICA}

nenhuma maneira, a aceitação irresponsável de uma "panprincipiologia oportunista", cuja discricionariedade ilimitada se afasta dos próprios feixes de valores constitucionais. Propiciar tal poder ao Estado-Juiz é rasgar todos os valores albergados pela Magna Carta. A onisciência e a onipotência de uma forma de poder é indício de transfiguração democrática e da criação de um superpoder do Estado, segundo caracteres especialmente "maquiavélicos".

Ao contrário do que originalmente propõe-se, uma constitucionalização "aleatória" do Direito pode levar: a) Do ponto de vista político, à tirania da minoria, instrumentalizada pela obliteração da legislação ordinária; b) Do ponto de vista epistemológico, à sacralização do decisionismo maquiavélico - ativismo ilimitado do Poder Judiciário. Nesse sentido, a advertência de Galvão (2014, p. 312), segundo a qual, o mau uso dos Princípios, no limite, conduziria ao fim do Estado de Direito e seu principal Princípio informador - a legalidade: “(...) Ao dissipar a densidade normativa das normas jurídicas e autorizar os juízes a decidirem com base em preferências pessoais, o neoconstitucionalismo golpeia com intensidade o conceito de Estado de Direito, aproximando-o do fim" (GALVÃO, 2014, p. 312). Sobre isso, comenta Lenio Streck (2013, posição 1742):

(...) não é (mais) necessário dizer que o "juiz não é a boca da lei", etc., enfim, podemos ser poupados, nesta quadra da história, dessas "descobertas polvolares". Isto porque essa "descoberta" não pode implicar um império de decisões solipsistas, das quais são exemplos as posturas caudatárias da jurisprudência dos valores (que foi importada de forma equivocada da Alemanha), os diversos axiologismos, o realismo jurídico (que não passa de um "positivismo fático"), a ponderação de valores (pela qual o juiz escolhe um dos princípios que ele elege prima facie), etc. [grifo do autor].

Mesmo o STJ, já decidiu que os julgadores não devem atender às suas convicções pessoais:

I - PROCESSUAL - STJ - JURISPRUDÊNCIA - NECESSIDADE DE QUE SEJA OBSERVADA. - O Superior Tribunal de Justiça foi concebido para um escopo especial: orientar a aplicação da lei federal e unificar-lhe (sic!) a interpretação, em todo o Brasil. Se assim ocorre, é necessário que sua jurisprudência seja observada, para se manter firme e coerente. Assim sempre ocorreu em relação ao Supremo Tribunal Federal, de quem o STJ é sucessor, nesse mister. Em verdade, o Poder Judiciário mantém sagrado compromisso com a justiça e a segurança. Se deixarmos que nossa jurisprudência varie ao sabor das convicções pessoais, estaremos prestando um desserviço a nossas instituições. Se nós - os integrantes da Seção - não observarmos as decisões que ajudamos a formar, estaremos dando sinal para 
que os demais órgãos judiciários façam o mesmo. Estou certo de que, em acontecendo isso, perde sentido a existência de nossa Corte. Melhor será extingui-la. (...). STJ, $2^{\text {a }}$ Seção, AgRg nos EREsp 593.309/DF, rel. Min. Humberto Gomes de Barros, j. 26.10.2005, DJe 23.11.2005, p. 154. [o grifo é nosso].

Entretanto, essa vedação às decisões irracionalistas não podem, no extremo, significar o seu oposto radical. Ou seja, querer que a decisão do juiz se torne uma "fórmula matemática", desprovida do seu substrato humano. A decisão judicial é um "acontecer”, que se dá na história jurídica de seus precedentes.

\section{O CONTROLE DIALÓGICO DA FUNDAMENTAÇÃO DAS DECISÕES JUDICIAIS}

A fundamentação das decisões judiciais é matéria própria de constituição e, em nossa Constituição de 1988, está expressamente consignada no art. 93, IX, CRFB/88. De sorte, a motivação das decisões judiciais é direito fundamental do jurisdicionado, cominando-se "pena" de nulidade para as decisões não fundamentadas.

Para Didier Jr., Braga e Oliveira (2015, p. 314), a fundamentação da decisão judicial deve atender ao conteúdo processual da verdade possível, qual seja aquela necessária e suficiente para uma decisão justa; "mas, sempre e necessariamente, a verdade" [o grifo é do autor]. Para mais, Didier Jr., Braga e Oliveira (2015, p. 315) expõem que a exigência da motivação das decisões judiciais tem uma função dupla:

Primeiramente, fala-se numa função endoprocessual, segundo a qual a fundamentação permite que as partes, conhecendo as razões que formaram o convencimento do magistrado, possam saber se foi feita uma análise apurada da causa, a fim de controlar a decisão por meio dos recursos cabíveis, bem como para que os juízes de hierarquia superior tenham subsídios para reformar ou manter essa decisão. Fala-se ainda numa função exoprocessual ou extraprocessual, pela qual a fundamentação viabiliza o controle da decisão do magistrado pela via difusa da democracia participativa, exercida pelo povo em cujo nome a sentença é pronunciada. Não se pode esquecer que o magistrado exerce parcela de poder que lhe é atribuído (o poder jurisdicional), mas que pertence, por força do parágrafo único do art. $1^{\circ}$ da Constituição Federal, ao povo. [o grifo é do autor]. 


\section{A FUNDAMENTAÇÃO DAS DECISÕES JUDICIAIS NO NOVO PROCESSO CIVIL BRASILEIRO: UMA QUESTÃO DE HERMENÊUTICA}

Pode-se, então, verificar-se que a fundamentação/motivação das decisões judiciais tem dois vetores essenciais: um vetor individualizado - dirigido às partes - e, um discurso coletivo - dirigido à formação do precedente. Disso, fazendo-se um estreitamento da Filosofia de HansGeorg Gadamer, do plano ontológico para o plano metodológico ${ }^{9}$, pode-se aceitar que a fundamentação da decisão judicial é, também, uma questão de hermenêutica filosófica ${ }^{10}$ : "refazer o caminho da fenomenologia do espírito hegeliana até o ponto em que, em toda subjetividade, se mostra a substancialidade que a determina" (GADAMER, 1999, p. 451, o grifo é nosso).

Ainda estreitando a filosofia gadameriana para a dimensão metodológica, pode-se afirmar que a fundamentação é uma espécie de jogo não aleatório, que deve primar pela integridade e coerência" ${ }^{11}$. No ato interpretativo, haverá, desde logo, "o primado do jogo em

\footnotetext{
${ }^{9}$ Utiliza-se a palavra "estreitamento", pois o "método hermenêutico" não se apresenta nos ditames de uma Teoria Metodológica aplicável às Ciências do Espírito. Em Gadamer, o "método" é a recondução do olhar do ente para o ser. O método traçado pela filosofia de Hans-Georg Gadamer é a diminuição da distância ontológica. Sobre isso, escreve Gadamer (1998a, p. 90): "Nem as extensões do apriorismo kantiano para lá dos limites da 'ciência natural pura' por obra dos neokantianos, nem a nova interpretação das ciências experimentais modernas podem anular a concepção fundamental de Kant: somos cidadãos de dois mundos. Estamos, não só do ponto de vista sensível, mas também 'supra-sensível', destinados à liberdade - embora estes conceitos da tradição platônica só designem a posição dos problemas e não possam fornecer a solução da tarefa proposta com o primado da razão prática. Enquanto o facto da liberdade se deve pensar, com Kant, como um fato da razão, a teoria da evolução inscreve-se no âmbito da razão 'teórica'. A liberdade, pelo contrário, não é objeto da experiência, mas antes pressuposto da razão prática".

${ }^{10} \mathrm{Em}$ contrapartida ao conceito de experiência apresentado pelas ciências do espírito e sociais, quando tentam objetificar pelo "método histórico" (análogo ao das ciências naturais) o seu objeto de estudo, Gadamer vem trazer a sua concepção de experiência hermenêutica. Gadamer traz "o seu conceito histórico e dialético de experiência, cuidadosamente enunciado; neste conhecer não é simplesmente um fluxo de percepções, mas um acontecimento, um evento, um encontro" (PALMER, 1999, p. 197). Gadamer, apesar de não concordar com os pressupostos e conclusões de Hegel acredita que a avaliação que este faz da experiência é o ponto de partida da sua hermenêutica dialética (PALMER, 1999, p. 198). A interpretação da compreensão como uma ontologia, na qual todo o saber advém de um dado histórico prévio, remonta a visão hegeliana de "substância", porque "suporta toda opinião e comportamento subjetivo e, com isso, prefigura e delimita toda a possibilidade de compreender uma tradição em sua alteridade histórica" (GADAMER, 1999, 451). Assim, nas raízes heideggerianas do pensamento de HansGeorg Gadamer, está a presença da estrutura dialética da consciência provocada por Hegel. O conceito de abertura próprio da linguagem e a possibilidade de todo discurso transcender continuamente seu horizonte interpretativo vão ser fundamentados na conduta dialética da consciência, proposta por Hegel na Fenomenologia do Espírito. Por outro lado, Gadamer não aceita em Hegel a culminância em um Espírito Absoluto que a tudo determina e que estabelece as coisas do mundo e as consciências singulares como um refratar dele mesmo, enquanto tudo que é. Essa essencialidade dialética não se esgota em uma autoconsciência total, ou como afirmava Hegel: "a consciência, ao abrir caminho rumo à sua verdadeira existência, vai atingir um ponto onde se despojará de sua aparência: a de estar presa a algo estranho, que é só para ela, e que é como outro. Aqui aparência se torna igual à essência, de modo que sua exposição coincide exatamente com esse ponto da ciência autêntica do espírito. E, finalmente, ao apreender sua verdadeira essência, a consciência mesma designará a natureza do próprio saber absoluto" (HEGEL, 2001, p.73). Sob esse aspecto Gadamer questiona a dialética quanto a seu status de saber absoluto, dado que sua hermenêutica aponta na direção de um questionamento que a dialética deve procurar trazer para si, repreendendose e corrigindo-se (ALMEIDA, 2000, p. 110).

${ }^{11}$ Apesar de se utilizar uma contextualização metodológica para a apresentação do "jogo" interpretativo, sabe-se que o conceito de jogo (spiel) em Gadamer (1999) não se presta à experiência metodológica, pois que atinge uma dimensão ontológica. Em Gadamer, o conceito de jogo diz respeito à forma própria de dasein ser, qual seja: “jogada (atirada) do Ser” e na - relação com o Ser: “[...] a vontade de o indivíduo reservar-se ou abrir-se já não é
} 
face da consciência do jogador [...]” (GADAMER, 1999, p. 194). A tarefa judicial não servirá à mera retórica, provocando métodos e articulando "planos poderosos" para justificar um objeto “já decidido". Assim:

[...] o comportamento do jogador não deve ser entendido como um comportamento da subjetividade, já que é antes, o próprio jogo o que joga, na medida em que inclui em si os jogadores e se converte desse modo no verdadeiro subjectum do movimento lúdico [GADAMER, 1999, p. 708, o grifo é do autor].

Na decisão judicial, portanto, haverá uma experiência dialógica, onde não existe uma decisão integralmente livre, resultante de um esforço não compartilhado e totalmente objetivo. Na lição de Didier Jr., Braga e Oliveira (2015, p. 318):

[...] Enfim, não se trata de uma exposição lógico-demonstrativa, muito menos, retórico-persuasiva, mas, sim, uma que atenda aos requisitos de validade de uma argumentação prática, isto é, a congruência, a coerência, o emprego adequado da linguagem comum e jurídica, a observância de regras de inferência etc., [...], cuja racionalidade exige que sejam objetivamente aceitos e compartilhados [o grifo é nosso].

Dessa maneira, pode-se considerar que a tarefa de fundamentação remete à encarnação de sentido para os diferentes "cânones racionais" de um tempo e de um lugar em que se atua (DIDIER JR.; BRAGA; OLIVEIRA, 2015, p. 317). A fundamentação é aplicação, estabelecendo sentido para a situação concreta. Na aplicação, não se julga a partir de juízos externos a si, em uma situação não afetada, mas dentro de uma relação específica, que vincula os intérpretes. Fundamentar é interpretar; interpretar é aplicar, onde "nossas considerações nos forçam a admitir que, na compreensão, sempre ocorre algo como uma aplicação do texto a ser compreendido, à situação atual do interprete" (GADAMER, 1999, p. 460).

A aplicação não representa, simplesmente, relacionar a situação geral com a situação particular. Consiste em “encarnar” aquilo que a herança histórica da interpretação (precedentes)

\footnotetext{
determinante para o modo de entrarmos em diálogo mútuo e de sermos levados por ele. O determinante é a lei da coisa [do Ser] que está em questão (Sache) no diálogo, que provoca a fala e a réplica e acaba conjugando a ambas. Assim, quando se dá o diálogo sentimo-nos plenos [...]" (GADAMER, 2002, p. 180). Por isso, Palmer (1999, p. 176) explica que: "Por 'jogo' Gadamer não entende uma atitude ou uma atividade de um sujeito humano que cria e se diverte; também não considera o jogo como a 'liberdade' da subjetividade humana que se empenha na própria brincadeira". Para Gadamer (1999, p. 174) o "Jogo" reporta-se ao modo de ser da obra de arte, funcionando como "fio condutor da explicação ontológica" (1999, p. 174).
} 


\section{A FUNDAMENTAÇÃO DAS DECISÕES JUDICIAIS NO NOVO PROCESSO CIVIL BRASILEIRO: UMA QUESTÃO DE HERMENÊUTICA}

diz ao caso concreto, em estado de desvelamento. Revive-se, no contexto jurídico, o logos argumentativo grego e o conceito de Paidéia $^{12}$, onde a ética não é uma disciplina das Ciências do Espírito, apartada do jurídico. Nessa exegese, o jurídico se realiza "no estilo da ética e das ciências sociais” (DIDIER JR.; BRAGA; OLIVEIRA, 2015, p.317).

De sorte, há um conteúdo "de vinculação" em toda decisão judicial, resultado do círculo hermenêutico dos precedentes ${ }^{13}$, que se exterioriza nos necessários princípios racionais da coerência, consistência, segurança jurídica e aos valores fundamentais "incorporados" às Constituições dos Estados Nacionais. Zaneti Jr. (2016, p. 138) explica que é imprescindível certo "ceticismo moderado" ao intérprete:

O "cético moderado" tem o dever de interpretar a lei e aplicar o direito, consciente de que está fazendo uso ativo e dinâmico dos direitos fundamentais estabelecidos na constituição como valores fundamentais positivados, estado vinculado às leis e aos precedentes que exerceram antes a mesma tarefa, os quais excluem os significados considerados absurdos e consideram do ponto de vista, inclusive da tradição hermenêutica, os significados expressos na norma.

Dito isso, não seria despiciendo postular a existência de uma "dimensão ético-estética" na jurisprudência, sendo equivocado depositar nos precedentes uma dimensão insuladamente criativa, como se estivesse "liberta" de sua integridade para com a Constituição e para com as Leis. Consigna-se, portanto, a crucial construção de limites e de vínculos para os diferentes contextos e momentos interpretativos. Nesse sentido, a lição de Gadamer (1998b, p. 65-66):

A caracterização [compreensiva] pela relação circular deve ser, [...] complementada por uma determinação suplementar que eu expressarei de

\footnotetext{
${ }^{12}$ Segundo Nadja HERMANN (2001, p. 21) “o termo grego paidéia $(\pi \alpha 1 \delta \varepsilon 1 \alpha)$ não tem equivalente em nossa língua. [...] O termo paidéia adquire, ao longo da antiguidade grega, um sentido de formação da perfeição humana, de perfeição espiritual do homem grego". A paidéia (ou formação) grega representa aquela tentativa (formativa) de criar condições para uma sociedade justa, onde os indivíduos estariam dispostos "de acordo com a ordem de um cosmos racional. [...] A paidéia passa a ser a educação para a virtude” (2001, p. 23, 24) buscando a identificação do homem com sua alma, com sua natureza espiritual, exigindo-se dele um conhecimento de si e o exercício profícuo de uma razão voltada para as questões humanas reais e permanentes, pois que "o verdadeiro homem está na alma, a sede de todos os valores humanos" .

13 Gadamer adverte que as características pré-conceituais [no nosso caso, os precedentes] estão em constante reorientação, permanecendo em jogo, jamais cedendo às pressões da completa reflexão em nome da soberania da certeza racional. A compreensão pressupõe uma pré-compreensão e ela não ocorre sem uma dimensão projetiva que antecipa o sentido: "[...] O círculo hermenêutico é um círculo rico em conteúdo (inhaltlich erfülltt) que reúne o intérprete e seu texto numa unidade interior a uma totalidade em movimento (processual whole). A compreensão implica sempre uma pré-compreensão que, por sua vez, é prefigurada por uma tradição determinada em que vive o intérprete e que modela os seus preconceitos"13 (GADAMER, 1998b, p.13). Dessa feita, para Gadamer os conceitos prévios não constituem algo que possamos aceitar ou recusar, mas eles são a base da capacidade que temos para compreender a história (PALMER, 1999, p. 185-186).
} 
bom grado como a antecipação de uma "coerência perfeita". [...] O guia de nossa compreensão, a antecipação de uma coerência perfeita. [....] não é apenas uma unidade do sentido imanente que pressupõe a operação concreta da compreensão: toda compreensão de um texto pressupõe que ela seja orientada por expectativas transcendentais, cuja origem deve ser buscada entre a intenção do texto e a verdade.

Ora, a Teoria dos Precedentes, como "modus operandi” da decisão judicial, trata de estabelecer mecanismos de controle das arbitrariedades das decisões judiciais. As Cortes judiciais devem estar vinculadas aos próprios precedentes, do ponto de vista do ônus argumentativo, para afastá-lo, ou, para superar um precedente antigo na sua aplicação atual (Cfe. ZANETI Jr. 2016, p. 291).

Opera uma dimensão "estética" da decisão judicial, que é a sua dialogicidade intrínseca. Segundo Gadamer (2002, p. 180), a dialogicidade segue uma formulação, que se fundamenta naquele supracitado conceito de jogo, que é "[...] processo dinâmico (cinético) que abarca os jogadores ou o jogador" (GADAMER, 2002, p. 180). Trata-se de resgatar, no Direito, a centralidade ético-estética da justiça ${ }^{14}$, colocando a questão dos valores, além de qualquer cognitivismo ou intelectualismo. Assim, assevera Gadamer (2001, p. 58):

[...] É a factualidade de convicções, valorações e hábitos íntima e profundamente compreensíveis, íntima e profundamente comuns, a suma de tudo o que constitui o nosso sistema de vida. A palavra grega para este complexo de tais factualidades é o bem conhecido conceito de ethos, do ser que se transformou através do exercício e do hábito. Aristóteles é o fundador da ética, porque honrou como determinante este caráter da factualidade.

\footnotetext{
${ }^{14}$ É importante reiterar que o sentido ético-estético em Gadamer é ontológico e não se "estreita" nas metodologias das Ciências do Espírito. A interrogação sobre o ser do homem, sobre sua natureza, sobre o seu sentido pode ser considerada como o princípio iluminador das diferentes interrogações de Gadamer. A sua mensagem é ontológica, revelada como verdadeiro projeto de esperança no humano. Essa mensagem é mais do que nunca atual e provoca expressivas reflexões: "Não sei, afinal, quais respostas se dará um dia à humanidade, para a vida conjunta do homem, em relação ao direito do individuo e ao direito da coletividade, à violência que nasce da família ou do Estado. [...] Assim é que, por todo lado, há especificidades e singularidades de uma estranheza intransponível no mundo. O que nos permite apenas dizer: se não aprendermos a virtude da hermenêutica, isto é, se reconhecermos que se trata, em primeiro lugar, de compreender o outro, a fim de ver se, quem sabe, não será possível, afinal, algo assim como solidariedade da humanidade enquanto um todo, também, no que diz respeito a um viver junto e a um sobrevir com o outro, então - se isso não acontecer - não poderemos realizar as tarefas essenciais da humanidade, nem no que tem de menor, nem no que tem de maior". (GADAMER, 2000a, p.25).
} 


\section{A FUNDAMENTAÇÃO DAS DECISÕES JUDICIAIS NO NOVO PROCESSO CIVIL BRASILEIRO: UMA QUESTÃO DE HERMENÊUTICA}

Ora, o ethos da decisão judicial é sua vinculação aos limites do ordenamento constitucional. Os precedentes, admitidos como "fontes do direito", estão "muito longe de constituir um indício de que o juiz cria o direito a partir de sua própria vontade. Nesta perspectiva, a força obrigatória do precedente, ou a admissão do precedente como fonte do direito, não significa que o judiciário tem o poder para criar o direito" (MARINONI, 2010, p. 38-39).

O diálogo histórico dos precedentes constitui um sistema de precedentes. Esse sistema é, por isso mesmo, operativo-criativo e, mediado por sua historicidade intrínseca, controlável contra as arbitrariedades de uma razão subjetivista egocêntrica. Nesse diapasão Zaneti Jr. (2016, p. 300) leciona:

Ora, a Constituição, em um Estado Democrático Constitucional, representa a unidade normativa do ordenamento jurídico, do qual são núcleo irradiante os direitos fundamentais. Ela estabelece limites e vínculos materiais/substanciais ao legislador e aos intérpretes do direito. Seu caráter de norma supraordenada, além de significar a existência do potencial direito ilegítimo, insere um elemento nomostático no próprio ordenamento. Isto quer dizer que os ordenamentos constitucionais contemporâneos são constituídos por uma dupla feição: nomostáticos e nomodinâmicos. Nomostáticos, estáveis, do ponto de vista do controle substancial de conteúdo das normas a

partir

dos princípios de direito natural positivisados nas Constituições como di reitos fundamentais. Nomodinâmicos, com margem de discricionariedade, do ponto de vista formal e do reconhecimento da autonomia legislativa dentro das margens de liberdade de conformação material deixadas pelo ordenamento constitucional substancial. [o grifo é nosso].

A operatividade na circularidade hermenêutica dos precedentes foi "legalizada", através do arts. 489, § 1º, V, VI, 926 e 927 do CPC. O código de 2015 prevê que a decisão deverá promover a demonstração de seus fundamentos determinantes, para aplicar o precedente; de outro lado, para não aplicá-lo, a decisão deverá promover a demonstração da distinção (distinguishing) do caso "atual" em face do precedente ou a superação (overruling) de seu entendimento (art.489, $\S 1^{\circ}, \mathrm{V}, \mathrm{VI}$, respectivamente; art. 926 e parágrafos; art. 927 e parágrafos, todos do CPC).

Dessa forma, a ratio decidendi (ou holding) deve demonstrar que os fundamentos determinantes do caso-precedente (precedente-identification) "se ajustam" ao caso-atual 
(precedente-folowing). As circunstâncias fáticas, que motivaram o precedente e que justificaram a sua edição (art. 926, $\S 2^{\circ}$, CPC), devem ser operativamente cotejadas diante do caso-atual, a fim de concluir pela adequação, ou não, do precedente à questão "nova". Ora, os efeitos vinculantes do caso-precedente são extraídos a partir da identificação dos fundamentos determinantes da decisão, na sua unicidade fático-jurídica. Por isso, é imprescindível estudarse a ratio decidendi dos julgados anteriores, que deve ser encontrável em sua fundamentação. Ora, são as razões de decidir que operam a vinculação. Delas, extrai-se uma "regra geral" que pode ser aplicada a situações análogas.

Os fenômenos da distinção (distinguishing) e da superação (overruling) mostram que a hermenêutica dos precedentes é operativo-criativa. Ao mesmo tempo, o sistema de precedentes é formalmente vinculante, na sua dimensão horizontal, haja vista os deveres de unidade, de estabilidade, de integridade e de coerência (art.926, do CPC). Para mais, se a vinculação formal horizontal abrange o próprio Tribunal “estabelecedor” do precedente, há uma vinculação formal vertical que atinge os Tribunais e Juízes hierarquicamente inferiores. Esclarece-se, ainda, que o CPC “elasteceu” essa vinculação “vertical”, quando estabeleceu que os Juízes e Tribunais também observassem a orientação do Plenário ou do Órgão Especial a que se vinculam (art. 927, V, CPC).

Do que se vê, a estrutura do sistema de precedentes é limite ao arbítrio judicial, com a eliminação ${ }^{15}$ do princípio do livre convencimento motivado ${ }^{16}$ (art. 371, CPC). Para Didier Jr., Braga e Oliveira (2015, p. 103), o silêncio do novo CPC é eloquente, ao retirar o advérbio “livremente” da expressão o Juiz apreciará a prova: “Art. 371. O juiz apreciará a prova constante dos autos, independentemente do sujeito que a tiver promovido, e indicará na decisão as razões da formação de seu convencimento". A questão nevrálgica é tentar impedir que o intérprete judicial tome decisões de modo alheio e indiferente ao sentido da norma constitucional, exagerando em seu poder discricionário, e passando a decidir para além dos limites da moldura constitucional.

\footnotetext{
${ }^{15}$ Didier Jr., Braga e Oliveira (2015, p.103) consigna que essa foi uma das mais importantes mudanças do ponto de vista simbólico do novo CPC, que foi "claramente inspirada nas provocações de Lênio Streck". De outro lado, há quem defenda a permanência do livre convencimento no novo CPC. Cfe. Fernando da Fonseca Gajardoni. Disponível em: <http://jota.info/olivreconvencimentomotivadonaoacabounonovocpc >. Acesso em: 02/05/2015.

${ }^{16}$ Sistema da livre convicção (prova livre ou íntima convicção): é o sistema mediante o qual o julgador, de maneira livre e soberana, poderá valer-se de elementos que, apesar de não constarem nos autos do processo, o levaram a determinado convencimento, não havendo a necessidade de motivar sua decisão.
} 


\section{A FUNDAMENTAÇÃO DAS DECISÕES JUDICIAIS NO NOVO PROCESSO CIVIL BRASILEIRO: UMA QUESTÃO DE HERMENÊUTICA}

Para a Doutrina de Lenio Streck (2007, p. 141): "não se pode confundir, (...), a adequada/necessária intervenção da jurisdição constitucional com a possibilidade de decisionismo por parte de juízes e tribunais".

Do mesmo modo, a Doutrina de Zaneti Jr. (2016, p. 364):

[...] o modelo de precedentes não é uma forma de liberar o juiz da lei, mas um método de vincular a discricionariedade do juiz na interpretação da lei, controlando a sua autoridade de forma democrática, tendo com parâmetros a universalização da decisão para os casos futuros (formação do precedente) e o já decidido nos casos anteriores (aplicação do precedente).

Segundo Gadamer ${ }^{17}$ a norma é desvelamento resultante da movimentação do intérprete na tradição histórica. Remete ao aspecto fundamental do movimento compreensivo: a questão da aplicação. Interpretar a norma implica buscar as relações daquela tradição normativa com o presente, procurando não somente trazer a sua significação literal, mas, também, considerar o significado da tradição para o momento atual ou o seu "nexo" com o "instante": "compreender é, então, um caso especial da aplicação de algo geral a uma situação concreta e particular" (GADAMER, 1999, p. 465, o grifo é nosso).

Os deveres de estabilidade, integridade e coerência remetem à concepção de unidade do Direito. Do exposto, o controle dialógico da decisão judicial exige a vinculação aos precedentes normativos, avançando para a "Nova Hermenêutica de concretização" (BONAVIDES, 2008, p. 672) oriunda do princípio da unidade da Constituição, que possibilita a introdução do conceito de juiz social, "enquanto consectário derradeiro de uma teoria material da constituição, e, sobretudo, da legitimidade do Estado social e seus postulados de justiça, inspirados na universalidade, eficácia e aplicação imediata dos direitos fundamentais" (BONAVIDES, 2008, p. 672). Ou seja, a operatividade histórica dos precedentes exige uma aceitação hermenêutica, que deseja ultimar um garantismo constitucional lúcido, oposto aos descalabros daquele intervencionismo estatal, que não observava a justa causa, a razoabilidade e a proporcionalidade de suas ações e, no plano processual, de suas decisões (art. $489, \S 2^{\circ}$, e art. $8^{\circ}$, do CPC). O princípio do devido processo legal exige, em sua acepção substantiva, que se consagre a decisão judicial “ético-estética”, primada pela concepção de igualdade substantiva e de justiças participativa e retributiva.

\footnotetext{
${ }^{17}$ Segue-se a mesma ideia de "estreitamento" do ontológico para o metodológico, usada ao longo deste trabalho.
} 


\section{3. À GUISA DE CONCLUSÃO: OS PRECEDENTES - UMA QUESTÃO DE HERMENÊUTICA E DE PROCESSO NA DIMENSÃO SUBSTANCIAL}

Ao longo desse texto, procurou-se estabelecer um estudo da exigência de fundamentação das decisões judiciais, por dentro da Teoria dos precedentes, como se apresenta no $\mathrm{CPC} / 2015$. Entretanto, a questão crucial do trabalho está na apresentação da "ratio decidendi" dos precedentes como uma questão de hermenêutica e de materialidade democrática.

Se, de um lado, em face do "neoconstitucionalismo" do pós-guerra, exigiu-se do Judiciário uma postura mais ativa, cumprindo-lhe compreender o caso particular em conformidade com os princípios e direitos fundamentais, outorgados pela Carta; de outro lado, essa atividade jurisdicional é limitada pela própria tradição constitucional dos precedentes. Nesse sentido, Zaneti Jr. ensina (2016, p. 361, os grifos são do autor):

[..] o intérprete não é livre, uma vez que tem o dever de seguir o precedente, mas que a ele é atribuído, justamente por exercer atividade tendencialmente cognitiva, o ônus argumentativo racional de afastar o precedente quando inaplicável (art. 489, $\S 1^{\circ}$, VI, ). Nenhum modelo ideológico puro pode ser aplicado à prática dos juízes brasileiros, mas é preciso garantir o constrangimento normativo a partir dos textos legais e dos precedentes formalmente vinculantes para que se reduza a discricionariedade judicial e aumente a racionalidade das decisões judiciais, objetivo principal de uma teoria garantista dos precedentes que integre as virtudes do constitucionalismo garantista e do Rule of Law, solução mais adequada ao Estado Democrático Constitucional.

O sistema de precedentes traz o vetor de universalização da norma criada na "ratio decidendi", bem como, abre-se à operacionalização da "distinção" (distinguishing) ou da "superação" (overruling) do precedente, diante do caso-atual (precedente-folowing). Por isso mesmo, o sistema de precedentes é círculo hermenêutico. Para Gadamer (1983, p. 65, o grifo é nosso): "o ponto central de toda compreensão se refere à relação objetiva que existe entre os enunciados do texto e nossa própria compreensão do assunto".

Através dessa ideia de universalização, o sistema de precedentes favorece a concepção de democracia substancial, assim conformada pela mediação entre as reivindicações atuais da sociedade e os valores inalienáveis do indivíduo, cuja relativização histórica não é sinônima de interesses exclusivos e particulares. Na relação entre intérprete e precedente (precedenteidentification), busca-se a "criação" de seu sentido normativo atual (precedente-folowing), por 


\section{A FUNDAMENTAÇÃO DAS DECISÕES JUDICIAIS NO NOVO PROCESSO CIVIL BRASILEIRO: UMA QUESTÃO DE HERMENÊUTICA}

dentro da estrutura histórico-constitucional do sistema, limitando a atuação exclusivamente relativista.

Do ponto de vista do processo judicial, sobreleva-se sua acepção substancial: cabe ao Poder Judiciário dar a tutela concreta do direito material, não, apenas, criando a "normaindividual", mas, sobretudo, primando pela efetivação do direito "reconhecido". Segundo Marinoni (2008, p. 136, os grifos são do autor):

O direito fundamental à tutela jurisdicional, além de ter como corolário o direito ao meio executivo adequado, exige que os procedimentos e a técnica processual sejam estruturados pelo legislador segundo as necessidades do direito material e compreendidos pelo juiz de acordo com o modo como essas necessidades se revelam no caso concreto.

Do exposto, verifica-se que o sistema de precedentes é questão de hermenêutica, pois possibilita ao Judiciário criar o Direito dentro da moldura constitucional ${ }^{18}$, ao passo que, também, permite a reconstrução desse Direito, dentro do processo de fundamentação/interpretação. Para mais, a ratio decidendi dos precedentes está na tensão hermenêutica entre sua universalidade (fonte do Direito) e sua aplicação ao caso-atual. Segundo Gadamer ${ }^{19}$ apud Almeida (2000, p.66):

[...] como se fossem duas pontas de um mesmo fio a coisa e o intérprete que a projeta estão, ao mesmo tempo, vinculados e distanciados, isto é, manifestam a tensão entre estranheza e familiaridade que os marca mutuamente. [...]

Também, o sistema de precedentes adotado pelo estatuto processual de 2015 busca viabilizar a racionalidade, a previsibilidade e, portanto, visa à concretização da "tutela autorizada e prometida pelo direito material", assim entendida como a tutela jurisdicional efetiva, concebida [e controlada] a partir da acepção/dimensão substancial do devido processo legal constitucional (Cfe. MARINONI, 2008, p. 141).

\footnotetext{
${ }^{18}$ Desde Kelsen, sabe-se que o intérprete tinha, ainda que nos casos “mais fáceis", uma moldura (frame) normativa a circundar o contexto da interpretação. Nos casos difíceis, nos quais os vetores interpretativos, insertos na moldura, são expressivamente mais numerosos, a tarefa pela "resposta" torna-se um trabalho hercúleo e que exige um compromisso de moralidade política.

${ }^{19}$ Segue-se a mesma ideia de "estreitamento" do ontológico para o metodológico, usada ao longo deste trabalho.
} 


\section{REFERÊNCIAS BIBLIOGRÁFICAS}

ALMEIDA, Custódio Luís Silva de FLICKINGER, Hans-Georg; ROHDEN, Luiz. Hermenêutica Filosófica: nas trilhas de Hans-Georg Gadamer. Porto Alegre: EDIPUCRS, 2000.

BARROSO, Luís Roberto. Fundamentos teóricos e filosóficos do novo direito constitucional (pós-modernidade, teoria crítica e pós-positivismo). In: A nova interpretação constitucional. Rio de Janeiro: Renovar, 2006.

BONAVIDES, P. Curso de direito constitucional. 23. ed. São Paulo: Malheiros, 2008.

CANOTILHO. José Joaquim Gomes. Direito Constitucional. Coimbra: Almedina, 1993.

DIDIER JR. F.; BRAGA, P.S.; OLIVEIRA, R. A. de. Curso de direito processual civil:

Teoria da prova, direito probatório, decisão, precedente, coisa julgada e tutela provisória. 10. ed. Salvador: Jus Podivm, 2015. v. 2.

GADAMER, Hans-Georg. A razão na época da ciência. Trad. Ângela Dias. Rio de Janeiro: Tempo Brasileiro,1983.

O problema da consciência histórica. Org. Pierre Fruchon; Trad. Paulo César Duque Herança e futuro da Europa. Trad. António Hall. Lisboa: Edições 70, 1998a. (Nova Biblioteca 70).

O problema da consciência histórica. Org. Pierre Fruchon; Trad. Paulo César Duque Estrada. Rio de Janeiro: Fundação Getúlio Vargas, 1998b.

Verdade e método: traços fundamentais de uma hermenêutica filosófica. Trad.

Flávio Paulo Meurer. 3. ed. Petrópolis, RJ: Vozes, 1999. (Pensamento Humano).

Da palavra ao conceito: a tarefa da hermenêutica enquanto filosofia. In: ALMEIDA, Custódio Luís Silva de.; FLICKINGER, Hans-Georg; ROHDEN, Luiz. Hermenêutica Filosófica: nas trilhas de Hans-Georg Gadamer. Porto Alegre: EDIPUCRS, 2000a. p. 13-26. (Filosofía, 117).

Elogio da teoria. Lisboa: Edições 70, 2001. (Biblioteca de Filosofia Contemporânea).

. Verdade e método II: complementos e índice. Tradução Ênio Paulo Giachini.

Petrópolis, RJ: Vozes, 2002. (Pensamento Humano).

GAJARDONI Fernando da Fonseca. O livre convencimento motivado não acabou no novo CPC. Disponível em: d <http://jota.info/olivreconvencimentomotivadonaoacabounonovocpc>. Acesso em: 02/05/2015.

GALVÃO, Jorge Octávio Lavocat. O neoconstitucionalismo e o fim do Estado de Direito. São Paulo: Saraiva, 2014. 


\section{A FUNDAMENTAÇÃO DAS DECISÕES JUDICIAIS NO NOVO PROCESSO CIVIL BRASILEIRO: UMA QUESTÃO DE HERMENÊUTICA}

HEGEL, G. W. F. Fenomenologia do espírito. (Parte I). Trad. Paulo Menezes. 6. ed. Petrópolis, RJ: Vozes, 2001.

HERMANN, Nadja. Pluralidade e ética em Educação. Rio de Janeiro: DP\&A, 2001.

HOBBES, Thomas. Leviatã: ou matéria, forma e poder de um estado eclesiástico e civil. São Paulo: EDIPRO, 2015.

LYOTARD, Jean-François. O pós-moderno. 4. ed. Rio de Janeiro: José Olympio, 1993.

MARINONI, Luiz Guilherme. Teoria geral do processo. 3.ed. São Paulo: Revista dos Tribunais, 2008.

MARINONI, Luiz Guilherme. Precedentes obrigatórios. São Paulo: Revista dos Tribunais, 2010.

MOREIRA, José Carlos Barbosa. "O que deve e o que não deve figurar na sentença”. In: Temas de Direito Processual - 8a série. São Paulo: Saraiva, 2004.

PALMER, R. E. Hermenêutica. Lisboa: Edições 70, 1999.

STRECK, Lênio Luiz. Hermenêutica jurídica e(m) crise. Porto Alegre: Livraria do Advogado, 2005 .

STRECK, Lênio Luiz. Verdade e consenso: Constituição, Hermenêutica e Teorias Discursivas. Da possibilidade à necessidade de respostas corretas em direito. $2^{\mathrm{a}} \mathrm{ed}$. Rio de Janeiro: Lumen Juris Editora, 2007.

STRECK, Lenio Luiz. O que é isto - decido conforme a minha consciência?. 4. ed. Porto Alegre: livraria do Advogadao, 2013.Kindle Edition.

ZANETI JR. Hermes. O valor vinculante dos precedentes: Teoria dos precedentes formalmente vinculantes. 2. ed. Salvador: Jus Podivm, 2016. 